\title{
The Density and Distribution of Serotonergic Appositions onto Identified Neurons in the Rat Rostral Ventromedial Medulla
}

\author{
Sonja B. Potrebic, ${ }^{1,2}$ Peggy Mason, ${ }^{2,4}$ and Howard L. Fields ${ }^{2,3}$ \\ ${ }^{1}$ The Program in Neuroscience, Harvard Medical School, Boston, Massachusetts 02143, 2Departments of Neurology \\ and Physiology and ${ }^{3}$ Keck Center for Integrative Neuroscience, University of California at San Francisco, San \\ Francisco, California 94143-0114, and ${ }^{4}$ Department of Pharmacological and Physiological Sciences and the \\ Committee on Neurobiology, University of Chicago, Chicago, Illinois 60637
}

\begin{abstract}
Neurons in the rostral ventromedial medulla (RVM) contribute to the modulation of nociceptive transmission and to the analgesic effects of opioids. The RVM contains serotonergic terminal arbors, serotonergic neurons and several types of serotonin (5-HT) receptors. Limited evidence suggests that 5-HT acting within RVM decreases nociceptive responsiveness and contributes to opioid analgesia. The present study examines the density and distribution of serotonergic afferents onto physiologically identified neurons in the RVM.

In anesthetized rats, RVM neurons were characterized by their response to noxious stimulation as either on (excited), off (inhibited) or neutral (unaffected) cells. Tissue containing intracellularly labeled RVM neurons was processed for 5-HT immunocytochemistry. Five off, five on, and three serotonergic neutral cells were examined with the confocal microscope for appositions between 5-HT immunoreactive (5-HT-IR) processes and intracellularly labeled processes. Serotonergic neutral cells had the highest density of 5-HTIR appositions. The density of 5-HT-IR appositions onto off cells was slightly lower. On cells demonstrated the lowest density of 5-HT-IR appositions.

These results indicate that 5-HT contributes to nociceptive modulation by direct actions on the activity of RVM cells. Because the RVM has several sources of serotonergic input and a number of different 5-HT receptor subtypes, further understanding of the role of RVM 5-HT afferents will require pharmacological studies to determine the action of 5-HT on each cell class and anatomical studies to determine the brainstem origin of serotonergic input to each cell class.
\end{abstract}

[Key words: 5-HT, pain modulation, raphe magnus, confocal microscopy, antinociception, immunofluorescence]

Through actions at multiple sites in the brainstem and spinal cord, serotonin $(5 \mathrm{HT})$ is believed to modulate nociceptive transmission (Basbaum and Fields, 1984; Le Bars, 1988; Fields et

\footnotetext{
Received June 10, 1994; revised Oct. 20, 1994; accepted Nov. 22, 1994.

This research was supported by PHS Grant NS 21445, the Bristol Myers Squibb Foundation, and the William M. Keck Foundation. We thank Drs. Yuh Nung and Lily Jan for use of their confocal microscope, Dr. H. J. Ralston for the use of his computerized data tablet and Aniko Zagon, Larry Ackerman, and Mechelle Williams for technical assistance.

Correspondence should be addressed to Dr. Peggy Mason, Department of Pharmacological and Physiological Sciences and the Committee on Neurobiology, University of Chicago, MC0926, 947 East 58th Strect, Chicago, IL 60637.

Copyright 91995 Society for Neuroscience 0270-6474/95/153273-11\$05.00/0
}

al., 1991) and to contribute to the analgesic effect of opioids (see Sawynok, 1988, for review). There is evidence that the rostral ventromedial medulla (RVM), a region which includes the nuclei raphe magnus and reticularis gigantocellularis pars alpha, is an important site for 5-HT actions. Serotonergic fibers and terminals are found throughout RVM (Fuxe, 1965; Steinbusch, 1981), as are a number of 5-HT receptor subtypes (Pazos et al., 1985; Hoffman and Mezey, 1989; Thor et al., 1990). Furthermore, excitatory and inhibitory responses of RVM neurons to iontophoretically applied 5-HT have been observed in vivo (Llewelyn et al., 1983; Davies et al., 1988a,b; Hentall et al., 1993) and in vitro (Pan et al., 1993). Microinjection of 5-HT into RVM produces antinociception in awake rats in some circumstances (Llewelyn et al., 1983; cf. Aimone and Gebhart, 1986) and pharmacological manipulations designed to increase 5-HT levels within RVM can also produce hypoalgesia in awake rats (Llewelyn et. al., 1984). However, since microinjection of 5-HT antagonists into RVM has no effect on nocifensor reflex latencies (Llewelyn et al., 1984; Kiefel et al., 1992a,b), tonic release of 5-HT in RVM may not contribute to basal nociceptive responsiveness.

There is also evidence that 5-HT acting within RVM contributes to opioid analgesia. An increase in RVM serotonergic metabolism, as measured by voltammetry, has been noted following systemic opioid administration (Rivot et al., 1989). Furthermore, RVM is required for the antinociception produced by microinjection of opioids into the PAG (for review, see Fields and Basbaum 1978; Basbaum and Fields, 1984), and microinjection of serotonergic antagonists into RVM attenuates the antinociception elicited by microinjection of morphine into the PAG (Kiefel et al., 1992a,b).

RVM neurons can be classified according to changes in activity which correlate with opioid administration and reflexes evoked by noxious stimuli (for review, see Fields et al., 1991). Off cells, which are proposed to inhibit nociceptive transmission, cease firing prior to noxious stimulus evoked withdrawal (Fields et al., 1983a) and become continuously active following opioid administration (Fields et al., 1983b). On cells increase their firing prior to a nocifensor reflex (Fields et al, 1983a) and are silenced by opioid administration (Barbaro et al., 1986); these cells may have a net facilitatory effect on nociception (see Fields 1992 for review). A third group of cells, neutral cells, show no change in activity which correlates with nocifensor reflexes or opioid administration. The demonstration that a subset of neutral cells are serotonergic suggests that serotonergic neutral cells 
may contribute to the inhibition of nociccption (Potrebic et al., 1994).

To establish a framework for understanding the action of 5-HT on RVM neurons, it is necessary to identify the neuronal targets of serotonergic afferents. Therefore, we combined intracellular labeling with 5-HT immunocytochemistry and confocal microscopy to analyze the density and distribution of 5-HT appositions onto RVM neurons.

\section{Materials and Methods}

Male Sprague-Dawley rats (250-400 gm) were used in all experiments. Animals were initially anesthetized with sodium pentobarbital $(60 \mathrm{mg} /$ $\mathrm{kg}$, i.p.) and were maintained in a light anesthetic state on $0.5-1.0 \%$ halothane in oxygen.

Methods for physiological recording in rats are similar to those previously described in cats (Mason et al., 1986, 1989, 1990) and will only be restated briefly. Glass micropipettes $(30-80 \mathrm{M} \omega)$ were filled with a solution of $2 \%$ Neurobiotin (Vector Laboratories, Burlingame, CA) in $0.1 \mathrm{M}$ Tris buffer ( $\mathrm{pH} \mathrm{7.4)}$ and $0.15 \mathrm{M} \mathrm{KCl}$. A posterior craniotomy was followed by aspiration of the cerebellar vermis. Microelectrodes were then lowered, under visual guidance, into the medulla at a $10-30^{\circ}$ angle to the coronal plane. Neurons were isolated by either spontaneous activity or resting membrane potential. Neurons were characterized by their response to a thermal stimulus applied to the tail and to noxious pinches to the tail, hindpaws, and nose. Noxious pinch was applied by toothed forceps at a pressure which was judged painful by the experimenters. Only neurons with a consistent response to noxious stimuli applied to the tail, hindpaws and nose were studied further. Neurons were labeled with Neurobiotin by injecting constant depolarizing current $(0.5-4.0 \mathrm{nA})$ for $30 \mathrm{sec}$ to $15 \mathrm{~min}$

Animals were sacrificed with a pentobarbital overdose and perfused with $200 \mathrm{ml}$ of saline followed by 1 liter of a fixative containing 4\% paraformaldehyde and $7 \%$ sucrose in $0.1 \mathrm{M}$ phosphate-buffered saline (PBS). The brainstem was removed, postfixed for 1 hr in fixative and cryoprotected overnight in $30 \%$ sucrose in $0.1 \mathrm{M}$ PBS. Coronal serial $50 \mu \mathrm{m}$ sections were cut on a freezing microtome. Intracellular Neurobiotin was visualized by reacting sections in $0.4 \%$ avidin (in $0.1 \mathrm{M}$ PBS, $0.5 \%$ Triton X-100) conjugated to Texas red (Vector Laboratories, Burlingame, CA) for $4 \mathrm{hr}$ at $4^{\circ} \mathrm{C}$. Sections were protected from light at all times.

Sections containing labeled neurons were processed for 5-HT immunocytochemistry. Rabbit anti-5-HT (INCStar, Stillwater, MN) was used at a final dilution of $1: 20,000$. Antiserum was diluted in buffer [0.1 M PBS, $0.3 \%$ Triton X-100, and $1 \%$ normal goat serum (NGS)]. Buffers for washing and dilution were the same unless noted. The diluted antiserum was incubated with $1520 \mathrm{mg}$ of acetone extracted rat liver powder overnight at $4^{\circ} \mathrm{C}$ and centrifuged to remove the precipitate.

The following steps were performed at $4{ }^{\circ} \mathrm{C}$ on a shaker. Sections were incubated in $50 \%$ ethanol for $30 \mathrm{~min}$ and transferred into buffer for three 10 min washes. Tissue was incubated in a solution of $3 \%$ NGS, $0.1 \mathrm{M}$ PBS, and $0.3 \%$ Triton $\mathrm{X}-100$ for $30 \mathrm{~min}$ before being transferred directly into the primary antibody solution for $48-72 \mathrm{hr}$. Sections were rinsed three times for $10 \mathrm{~min}$ in $50 \mathrm{ml}$ of PBS before being transferred to the secondary antibody solution [fluorescein goat anti-rabbit 1:250 (Vector Laboratories, Burlingame, CA), or $10 \mu \mathrm{g} / \mathrm{ml}$ of Bodipy goat anti-rabbit (Molecular Probes, Eugene, OR)] for 6-8 hr. Sections were washed once for $10 \mathrm{~min}$ in $50 \mathrm{ml}$ of PRS with $0.5 \%$ Triton X-100 and rinsed three times for $10 \mathrm{~min}$ in $50 \mathrm{ml}$ of PBS. Sections were mounted on unsubbed slides, air dried, coverslipped with $2 \%$ $n$-propyl gallate, and stored at $-20^{\circ} \mathrm{C}$

Two types of histological control experiments were performed. 5-HT antiserum was incubated overnight with $100 \mu \mathrm{g} / \mathrm{ml}$ of a $5-\mathrm{H} \mathrm{T}$-bovine serum alburnin conjugate (INCStar, Stillwater, MN). Preabsorbed antiserum substituted into the above protocol produced no specific staining. Second, when the primary antibody was omitted from the staining protocol, neither the Bodipy nor the fluorescein conjugated secondary antibody produced any staining.

Neuronal somata and dendrites were examined on a Bio-Rad confocal laser scanning microscope (MRC-600) using either a $60 \times$ or $63 \times$ apochromat objective. These objectives were corrected for both spherical and chromatic aberrations. A $7 \mathrm{mom}$ of 1.5 was employed in all cases. Two systems, equipped with either an argon (A1 and A2 filter set) or krypton-argon (K1 and K2 filter set) laser were used. The images obtained from both systems were comparable. No significant "bleed through" fluorescence was detected between the two filter sets.

Individual optical images were acquired in $1-1.5 \mu \mathrm{m}$ steps through the tissuc. The confocal apertures were set so that the optical section thickness was $1.5 \mu \mathrm{m}$ for the Texas red image and $1.9 \mu \mathrm{m}$ for the fluorescein or Bodipy signal. Both fluorophors were visualized simultaneously at each optical level. Though the optical thickness was slightly different for the two fluorophors, the optical sections were centered at the same section depth.

Coronal reconstructions were made from projected (summed) images of every scanned field. The summed images were photographed, printed at a magnification of approximately $600 \times$, and compiled onto a single reconstruction.

Dual images (intracellular and immunocytochemical labels) from each optical section taken through the tissue were merged using software provided by the manufacturer (Bio-Rad, Hercules, CA). Appositions were judged by visual inspection. For ambiguous contacts, a graph of half-maximal pixel intensity was used to judge whether an apposition existed, as detailed by Mason et al. (1992). The locations of all appositions were plotted on the coronal reconstructions of each cell.

In order to compute appositional densities, the surface area of the somata and dendrites were calculated with software provided by the manufacturer (Bio-Rad) using measurements of somatic perimeter taken every 1-3 $\mu \mathrm{m}$ throughout tissue where the soma was present. Surface area was calculated as the product of the perimeter and the distance between optical sections. Sections that contained the top or bottom of the soma contributed both a perimeter element and surface area measurement.

Dendritic length was measured from reconstructions using a computer linked drawing pad. Dendrites were subdivided, if necessary, into components of no longer than $400 \mu \mathrm{m}$. In addition, dendrites were subdivided at points where there was an abrupt change in diameter. The diameter at the proximal and distal ends of all dendritic segments was measured from the original confocal images using software provided by the manufacturer (Bio-Rad). Dendritic surface area (S.A.) for each segment was calculated according to the following formula for S.A. of a right angle cone:

$$
\text { S.A. }=\pi *\left(r_{p}+r_{d d}\right) *\left[l^{2}+\left(r_{p}-r_{d}\right)^{2}\right]^{0.5},
$$

where $r_{j}$ is the radius of the dendrite at its proximal end, $r_{d}$ is the dendrite radius at its distal end, and $l$ is the length of the dendrite segment.

All dendritic segments were assigned to one of four annuli, each one including $250 \mu \mathrm{m}$ of dendritic length. The central annulus included dendrites that radiated for up to $250 \mu \mathrm{m}$ from the soma. The second annulus included dendrites at lengths of $251-500 \mu \mathrm{m}$ from the soma and so on. The assignment of dendrites to an annulus was based solely on the coronal vector of the dendrite's path from the soma; no adjustment was made for dendritic travel in the sagittal plane.

The density of appositions was determined by dividing the number of appositions in the region of interest by the surface area of the intracellularly labeled processes in that same area. All data is presented as means \pm SDs. Since the data for each cell class was distributed normally (Lilliefors, NS for all groups) and since both $t$ and $F$ statistics are fairly insensitive to small deviations from a normal distribution, the densities for the three cell classes were compared using a one-way ANOVA followed by 'lukey's post hoc tests for pair wise comparisons. All statistics were calculated using SYSTAT 5.2.1 (Systat, Inc., Evanston, IL).

A variant of the "frame-shifted merge" method of Mason et al. (1992) was used to estimate the expected density of 5-HT appositions onto RVM neurons. This estimate is dependent upon the overall density of the 5-HT boutons in the region of interest. In order to estimate this expected density, optical sections were randomly selected from an on, off and ncutral cell. Each randomly selected optical section, containing an intracellularly labeled process(es), was merged with an optical section containing 5-HT-IR from a different focal plane, $6 \mu \mathrm{m}$ distant (in the $\mathrm{z}$-axis). The frame-shifted merges were examined by a naive observer and were interspersed with non-frame-shifted merges. The number of appositions seen in the frame shifted merges was divided by the total surface areas of the intracellularly labeled neuronal processes contained in these images $\left(2959 \mu \mathrm{m}^{2}\right)$ to give the expected density of 5-HT appositions within the RVM. For a subpopulation of RVM neurons, a density greater than the expected number indicates that the subpopulation is targeted by $5-\mathrm{HT}$ boutons. 

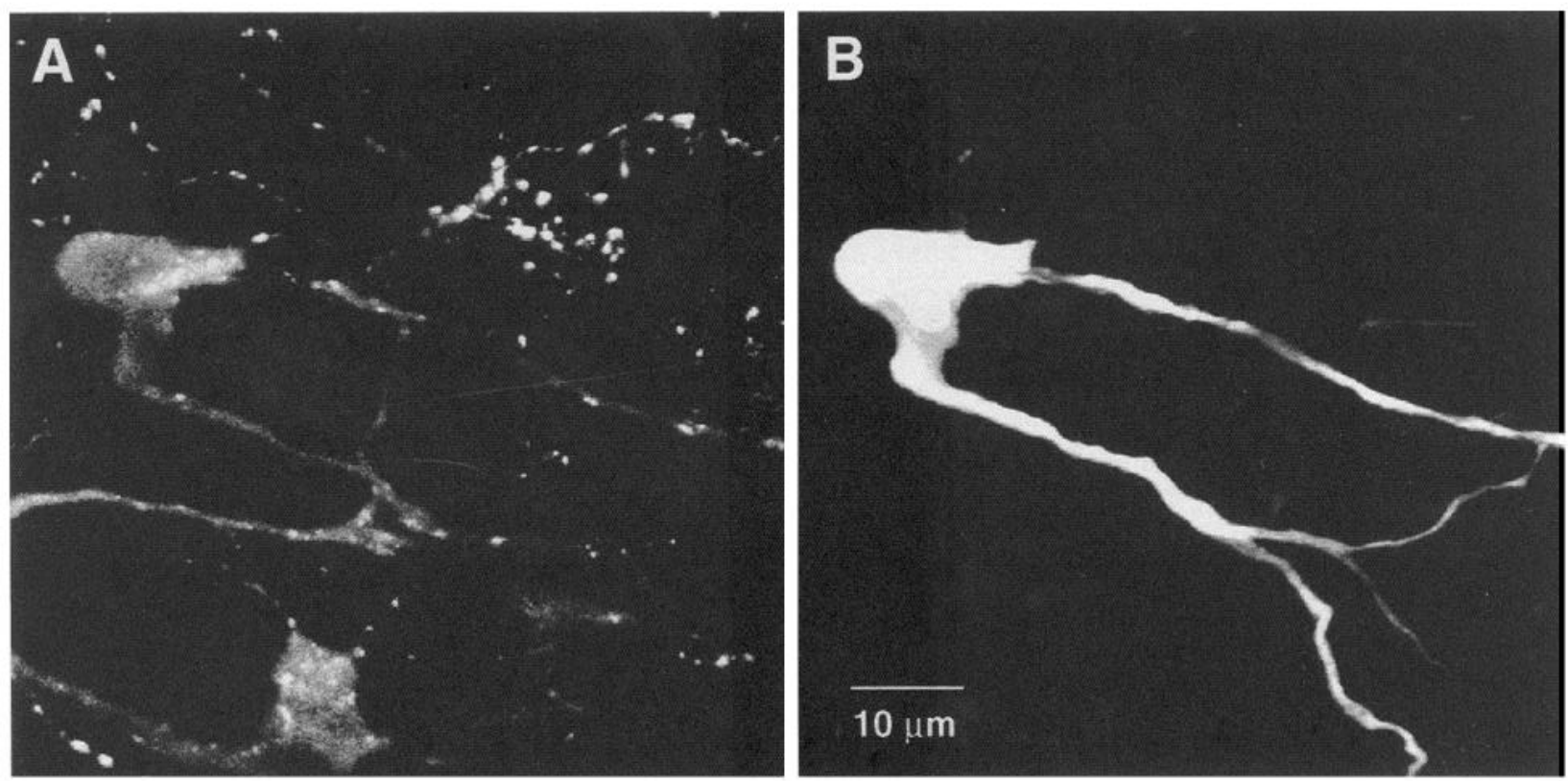

Figure 1. A, 5-HT immunoreactivity in RVM. Both cells and varicose axonal fibers are clearly visible. $B$, High power view of an intracellularly labeled neutral cell. The 5-HT immunoreactivity of this neuron is visible in the left panel. The image is a maximal projection, composed of 10 confocal optical sections. Both panels were imaged simultaneously.

Illustrations of appositions were obtained by printing confocal images which have been intensity adjusted for presentation. The figures represent either single optical sections or maximal projections, constructed from a stack of $2-12$ serial confocal optical images. In this type of projection, the pixel intensity at any point represents the maximum pixel intensity, found at that $x-y$ location, present in the $z$-axis series of serial confocal optical slices.

\section{Results}

These cells are part of a cohort described previously (Potrebic et al., 1994) in which the 5-HT-IR of intracellularly labeled neurons was examined. In the present study, the density and distribution of 5-HT-IR appositions onto a subset $(N=14)$ of the previously studied neurons is studied. This subset of cells was chosen because for each of the cells chosen, the dendritic arbor was well labeled. All statistics are based upon 13 cells which are contained in three physiological cell classes; one cell class (nonserotonergic neutral cells) containing only a single cell was thus omitted from statistical comparisons.

\section{Physiology}

Classification of RVM neurons as off, on or neutral cells was based upon changes in neuronal firing observed during the heat evoked tail flick reflex and in response to noxious pinch of the tail, hindpaws and nose (Fields et al., 1983a; Mason et al., 1990; Potrebic et al., 1994). Off cells decreased and on cells increased their firing rate in response to both noxious tail heat and noxious pinch applied to different body regions. Only cells with changes in neuronal firing that were both related to stimulus presentation and consistent in the sign of their response, at all stimulation sites, were classified as on or off cells. Neutral cells did not change their firing rate during trials of tail heat or noxious pinch. Units which were not spontaneously active and not excited by noxious stimulation were not studied further, since cells with this type of response profile could represent either silent off or neutral cells.

\section{Intracellular label}

Fourteen physiologically characterized, intracellularly labeled RVM cells - five off cells, five on cells, and four neutral cellswere analyzed in this study. An example of the appearance of the intracellular label imaged with the confocal microscope is shown in Figure $1 B$. The neurons were located in RVM at the level of the facial nucleus, (interaural levels from $-2.6 \mathrm{~mm}$ to $-1.8 \mathrm{~mm}$; Paxinos and Watson, 1986), with the majority being found within $300 \mu \mathrm{m}$ of the midline (Fig. 2). None of the intracellularly labeled on and off cells were serotonergic (see Fig. $3 F$ ); three of the four neutral cells demonstrated 5-HT-IR (see Figs. 1, 3C,D; Potrebic et al., 1994). Since only one nonserotonergic neutral cell was studied, this cell was omitted from the statistical analyses.

The somatodendritic morphology of on and off cells matches previously published descriptions (Mason et al., 1990; Potrebic and Mason, 1993). The dendrites of labeled on and off cells were long with few branches and extended primarily along the mediolateral axis (Fig. 4). The somatodendritic morphology of the single nonserotonergic neutral cell in our sample was similar in orientation and size to these two classes of neurons (Fig. 5). As can be seen by comparing the somatodendritic reconstructions in Figures 4 and 6, the serotonergic neutral cells appear smaller than the on and off cells. The total surface area of the serotonergic neutrals averaged $3618.0 \pm 377.9 \mu \mathrm{m}^{2}(n=3)$ and was less than that of the off cells $\left(11957.6 \pm 4841.7 \mu \mathrm{m}^{2}, n=\right.$ $5)$ or on cells $\left(15329.6 \pm 8168.6 \mu \mathrm{m}^{2}, n=5\right)$. One-way ANOVAs on the log transformed (in order to standardize the variance) surface area revealed that serotonergic neutral cells were smaller than on and off cells in total surface area $(F[2,10]=$ $7.7060, p=0.0094$, Tukey post hoc tests, ons vs neutrals $p=$ 0.0090 , offs vs neutrals $p=0.0259$ ). The dendritic surface area of serotonergic neutral cells was smaller than that of on cells but not of off cells (one-way ANOVA, $F[2,10]=5.9834, p=$ 0.0196 , Tukey post hoc tests, ons vs neutrals $p=0.0167$, offs 

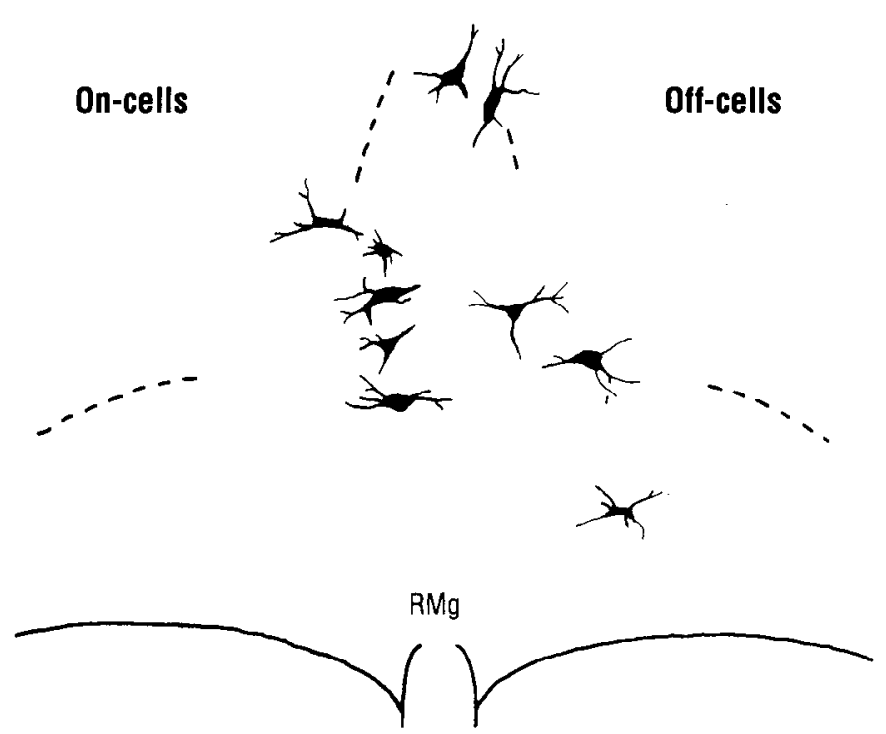

Neutral cells $+5 \mathrm{HT}$

Neutral cell, non $\mathbf{5 H T}$

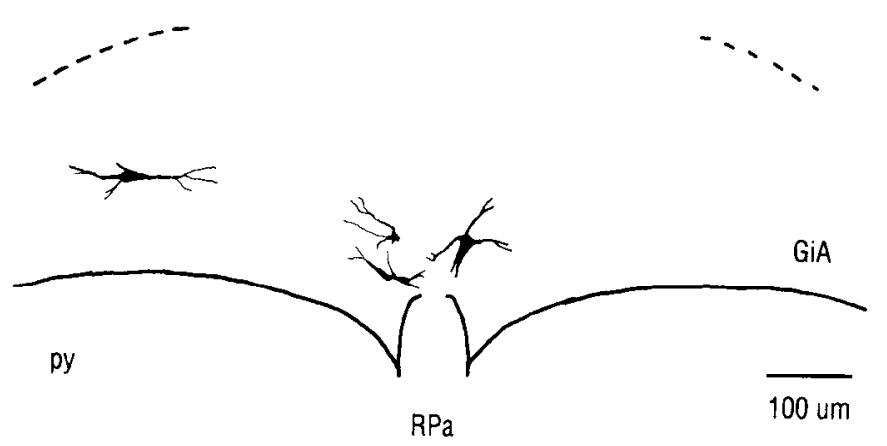

Figure 2. The locations of the 13 intracellularly labeled neurons are plotted on these schematics of RVM. Only the soma and proximal dendrites are shown. Some cells have been reversed mediolaterally for graphical purposes. Neurons are grouped according to cell type. The dashed lines represent the outline of the RVM region containing seroionergic neurons. $R M g$, nucleus raphe magnus; GiA, nucleus reticularis gigantocellularis pars alpha; $p y$, pyramidal tract; Rpa, nucleus raphe pallidus.

vs neutrals $p=0.0663$ ). The somatic surface area of all three cell types examined did not differ (one-way ANOVA, $F[2,10]$ $=3.5378, p=0.0689$ ).

Axons were identified for 9 of the 14 labeled cells. The axon was identified by (1) its thin, nontapering diameter, (2) by the presence of collaterals, and (3) by following it as it traveled outside the dendritic arbor. Axons that traveled outside of the region of the dendritic arbor were followed onto distant sections that were not analyzed in the present study. For these purposes, the axon was traced as it passed through serial sections that were processed using a diaminobenzidine reaction.

\section{5-HT immunocytochemistry}

Both 5-HT-IR neurons and fibers in RVM were labeled by our immunocytochemical protocol (Figs. 1A, 3). 5-HT-IR neurons were found in nucleus raphe magnus and in the nucleus reticularis gigantocellularis pars alpha, just dorsal to the pyramids (see also Fig. 2 in Potrebic et al., 1994).

In general, 5-HT-IR fibers were more widely distributed than 5-HT-IR neurons and were found throughout the RVM, in both nucleus raphe magnus and nucleus reticularis gigantocellularis pars alpha. Both nonvaricose fibcrs and fibcrs with axonal swellings were seen. Profiles which resembled boutons in size and shape, but without interconnecting fiber segments were also found. The distribution of immunoreactive neurons and fibers is in agreement with previous descriptions (Steinbusch, 1981).

\section{Serotonergic appositions onto RVM neurons}

Contacts between the intracellularly labeled neuronal processes and 5-HT-IR processes were identified by merging the digitized images obtained from the two fluorophors at each optical plane (see Materials and Methods and Fig. 3A). Appositions were defined as sites at which there were no unlabeled pixels between 5-HT-IR profiles and Texas red labeled processes (Fig. 3). Individual appositions could be seen either in single optical sections or, in the case of larger 5-HT-IR profiles, on two adjacent sections.

A 5-HT-IR profile apposing an intracellularly labeled process was considered an apposition if its diameter swelled to at least twice the width of its parent fiber or, if no interconnecting fiber was visible, it was larger than $0.3 \mu \mathrm{m}^{2}$. Profiles without interconnecting segments were differentiated from nonvaricose fibers imaged in cross section by a change in size and shape on adjacent optical sections.

\section{Density of 5-HT-IR appositions onto RVM neurons}

Although 5-HT-IR appositions were found on all cell types (Figs. 3-6), there was a differential density of appositions among on, off and serotonergic neutral cells (Fig. 7). Serotonergic neutral cells had the highest density of 5-HT-IR appositions, with a mean density of 16.1 appositions $/ 1000 \mu \mathrm{m}^{2}( \pm 3.9, n=3)$ of somatodendritic surface area. The density of 5-HT-IR appositions onto off cells was lower $\left(7.9 \pm 0.8 / 1000 \mu \mathrm{m}^{2}, n=5\right)$. The lowest density of 5-HT-IR appositions was seen in the on cell group $\left(5.2 \pm 1.0 / 1000 \mu \mathrm{m}^{2}, n=5\right)$. There was no overlap in the range of densities for 5-HT-IR appositions in these cell groups and the differences in density were found to be statistically significant between on, off, and serotonergic neutral cells (one-way ANOVA $F[2,10]=30.7406, p=0.0001$, 'lukey post hoc tests, $p=0.0002$ for on vs serotonergic neutral, $p=0.0006$ for off vs serotonergic neutral, $p=0.1133$ for on vs off) (Fig. 7A).

The difference in appositional density among the three cell groups reflects significant differences in the density of appositions on dendritic processes (one-way ANOVA $F[2,10]=$ 24.4117, $p=0.0001$, Tukey post hoc tests, $p=0.0003$ for on vs serotonergic neutral, $p=0.0012$ for off vs serotonergic neutral, $p=0.1781$ for on vs off) (Fig. $7 B$ ). In contrast, the density of somatic appositions was only different between serotonergic neutral cells and on cells (one-way ANOVA $F[2,10]=5.7709$, $p=0.0216$, Tukey post hoc tests, $p=0.0185$ for on vs serotonergic neutral, $p=0.0716$ for off vs serotonergic neutral, $p$ $=0.6169$ for on vs off) (see Fig. 7C).

Axons were identified in five off cells and four on cells. The appositional density onto labeled axons averaged $6.67 / 1000 \mu \mathrm{m}^{2}$ $\left( \pm 1.65 / 1000 \mu \mathrm{m}^{2}, n=5\right)$ for off cells and $3.7 / 1000 \mu \mathrm{m}^{2}$ $\left( \pm 2.05 / 1000 \mu \mathrm{m}^{2}, n-4\right)$ for on cells.

The density of 5-HT-IR appositions was further analyzed in relation to dendritic branch order and somatodendritic annulus (see Materials and Methods). Within each cell group, appositional density did not appear to vary systematically with dendritic branch segment order (not shown). Reflecting their smalle1 size, labeled serotonergic neutral cells had processes that were 

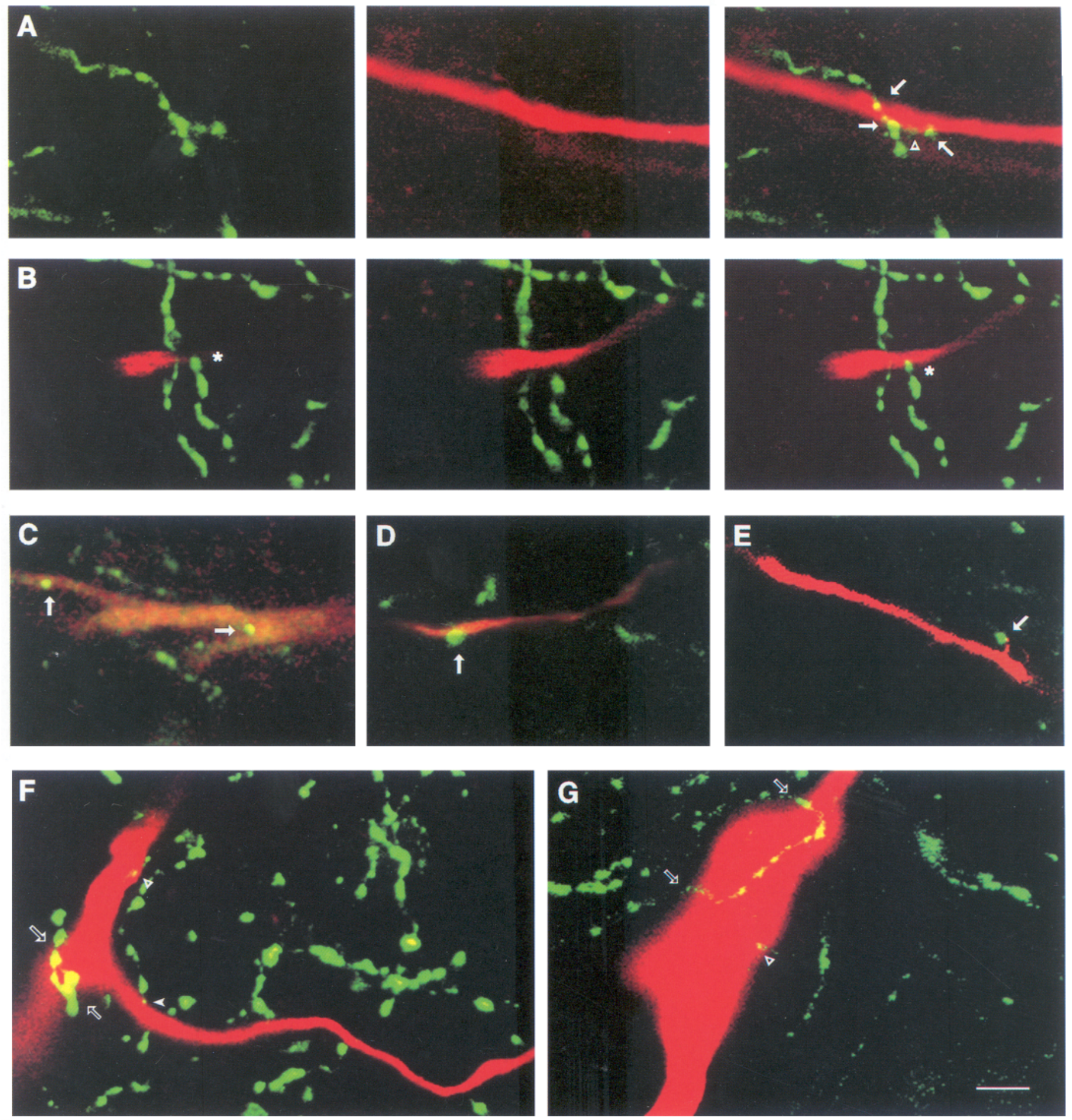

Figure 3. Pseudocolor confocal images. 5-HT-IR processes are green and the intracellular label is red. A, Confocal merging. The left most image shows 5-HT immunoreactivity in a single optical section. In the center is the complementary frame showing the Texas red labeled on cell dendrite. The right-most panel demonstrates a merge superimposing both images. Sites of apposition (arrows) appear as yellow in the merged image. The open triangle is below an apposition better visualized on an adjacent optical section. $B$, Near miss demonstrates the advantage of optical sectioning. The left-most and center images are two adjacent single section merged frames. Note that there are no appositions. When the two merges are stacked, an image (with signal from $3.8 \mu \mathrm{m}$ of tissue) is formed and a swelling (star) apposes the dendrite. The dendrite and swelling appear in different frames. $C$, Two appositions onto an intracellularly labeled 5-HT-IR neutral cell. Even though the neuron is serotonergic, appositions can be distinguished. D, Example of a 5-HT-IR apposition onto a 5-HT-IR neutral cell dendrite. 5-HT immunoreactivity is not visible in distal dendrites. $E$, 5-HT-IR apposition onto an off cell spine. RVM neurons have few spines, and only a small number of spines received 5-HT-IR appositions. $F$, RVM off cell. A varicose fiber (open arrows) makes multiple appositions onto the soma. The arrowhead points to a fiber crossing the axon. $G$, Nonserotonergic neutral cell. A single thin fiber (open arrows) contributes multiple appositions on the surface of the neuron's soma. In all images, the arrows point to appositions and the open triangles point to appositions better visualized on adjacent optical sections. Scale bar, $5 \mu \mathrm{m}$. 


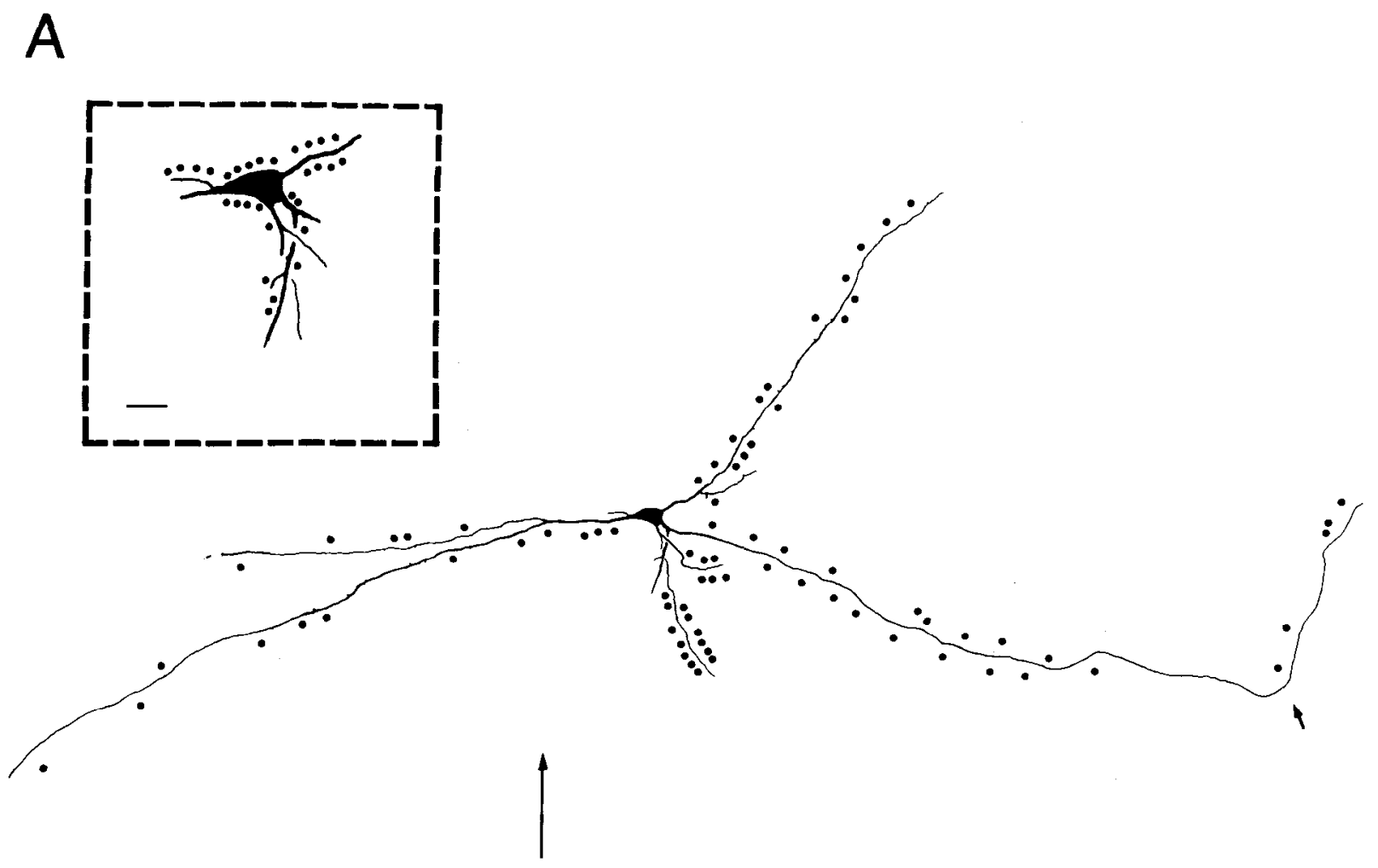

B

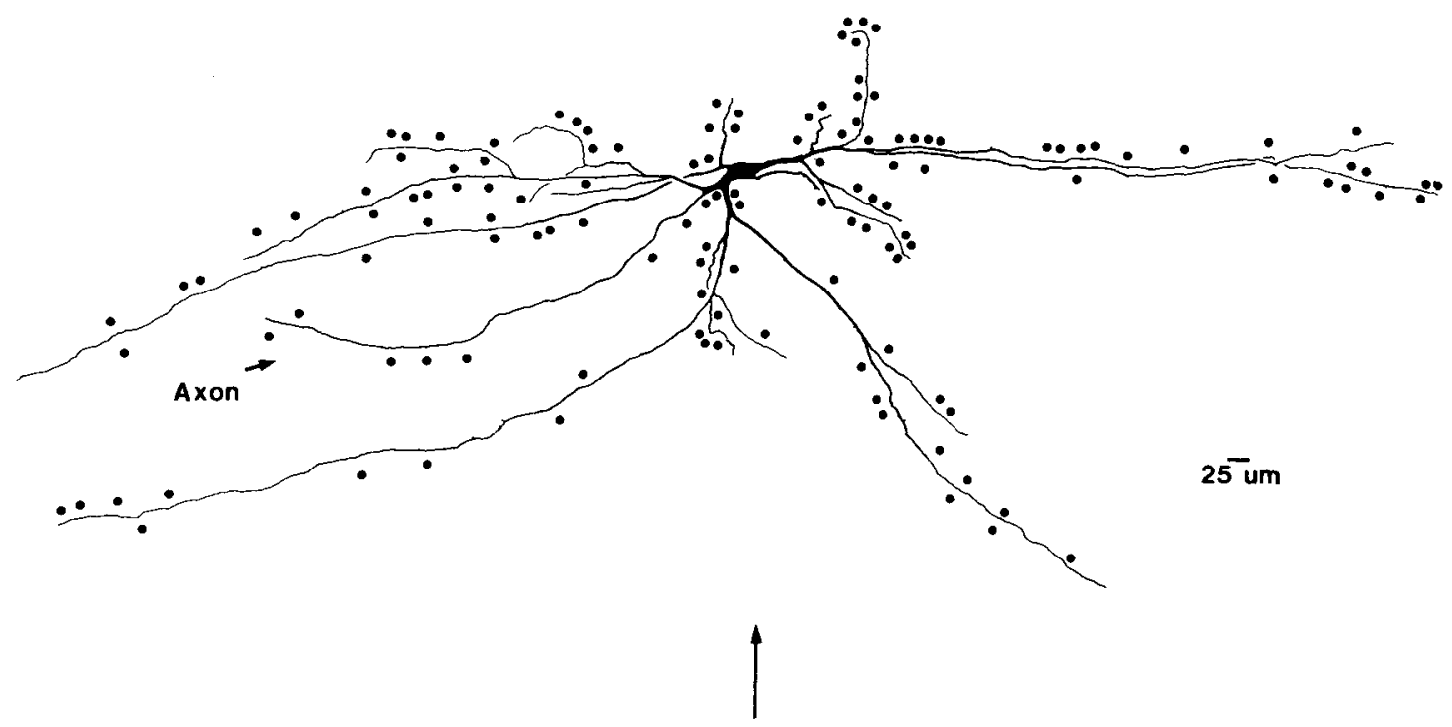

midline

Figure 4. The sites of 5-HT-IR appositions are mapped onto reconstructions of intracellularly labcled RVM ncurons. A, Off cell, The inset shows appositions onto the soma and proximal dendrites. $B$, On cell. In both figures, each dot represents a single apposition. The large size of the dot, in comparison to the actual size of axonal varicosities, obscures the low density of 5-HT appositions. The long vertical arrow marks the midline. The short arrow points to the axon. All scale bars are $25 \mu \mathrm{m}$. 


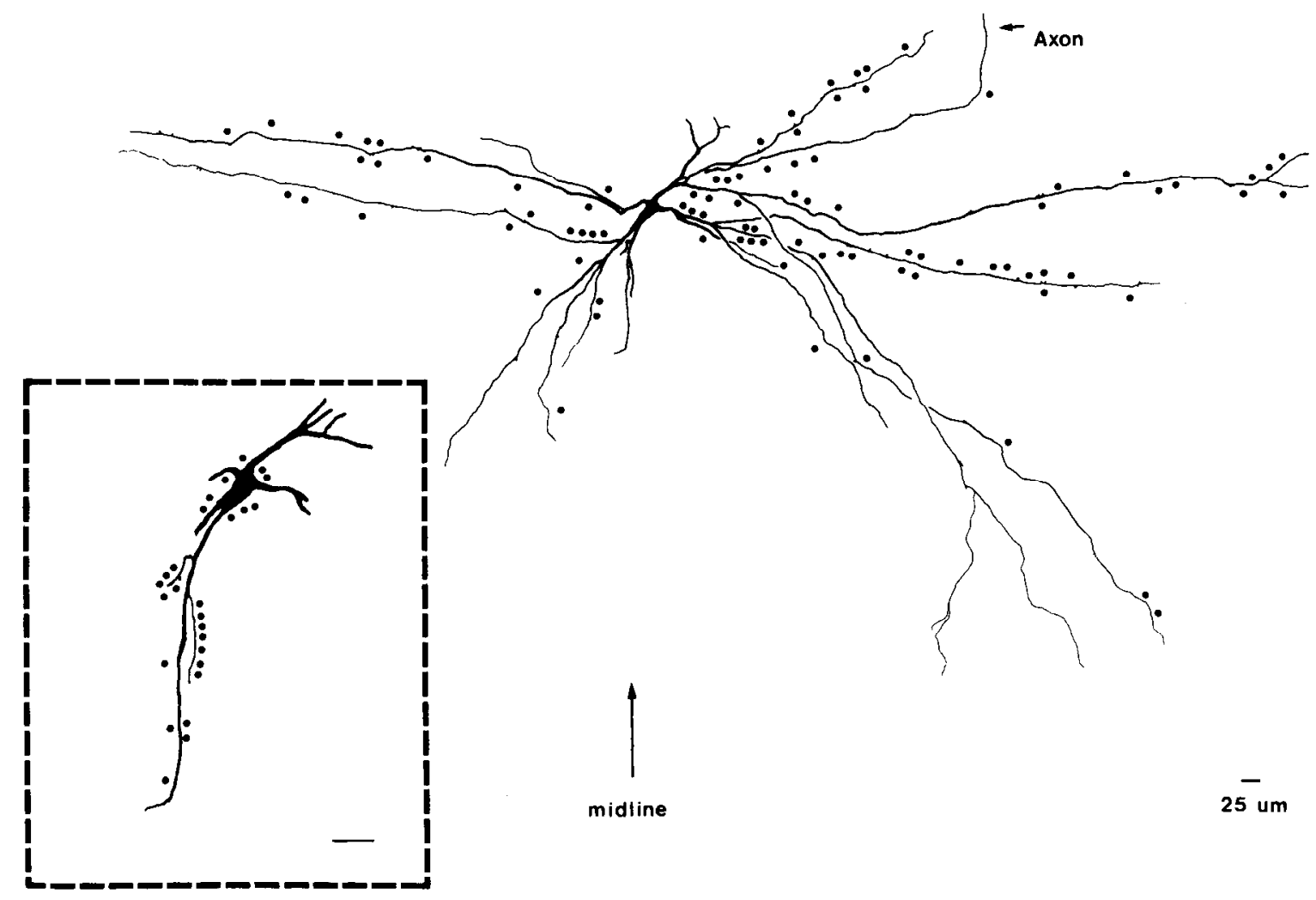

Figure 5. The distribution of 5-HT-IR appositions onto an intracellularly labeled nonserotonergic neutral cell is shown. The inset shows appositions onto the soma and a ventrally directed dendrite. Conventions as in Figure 4.

restricted to the first and second annuli, whereas labeled on and off cells had dendrites extending into the fourth annulus. There was no apparent pattern to the distribution of 5-HT-IR appositions onto individual cells, with regard to either dendritic branch order or annular location. For the central annulus, serotonergic neutral cells had a significantly higher appositional density as compared to on and off cells and off cells a higher density than on cells (one-way ANOVA $F[2,10]=30.7394, p=0.0001$, Tukey post hoc tests, $p=0.0002$ for on vs serotonergic neutral, $p=0.0010$ for off vs serotonergic neutral, $p=0.0460$ for on vs off) (see Fig. 8). Similarly, for appositions contained in the second annulus, on and off cells received fewer 5-HT-IR appositions than serotonergic neutral cells but were not different from each other (one-way ANOVA $F[2,8]=77.5321, p<0.0001$, Tukey post hoc tests, $p=0.0002$ for on vs serotonergic neutral, $p=0.0002$ for off vs serotonergic neutral, $p=0.7751$ for on vs off).

The one nonserotonergic neutral cell studied received 5-HTIR appositions (see Fig. 5). The 5-HT-IR appositional density onto this cell was 5.9 appositions $/ 1000 \mu \mathrm{m}^{2}$, a value that is within the range found for on cells.

\section{Pattern of 5-HT-IR appositions onto RVM neurons}

The pattern of appositions on labeled RVM neurons is best described as patchy and diffuse. While individual isolated appositions were found on dendrites of every cell, many appositions were clustered in groups of two to nine (Fig. 3). Additionally, although most single fibers appeared to contribute a single apposition, some individual axonal segments contributed multiple (range 2-8) contiguous appositions onto one labeled cell. In most such cases, fibers contributing more than one apposition contacted a single dendrite or soma. In a small number of cases, the same axonal collateral contributed to appositions onto the soma and adjacent primary dendrites or onto adjacent dendritic branch segments. However, it must be noted that no specific attempt was made to reconstruct individual fibers; only fibers that could be easily followed were studied in this way. Therefore, the number of fibers from which multiple appositions arise is probably underestimated by our method of analysis.

Serotonergic neutral cells and off cells had the highest percentage of dendritic branch segments with appositions; $73 \%$ of individual branch segments received at least one serotonergic apposition. On cells had slightly more "bare" dendritic segments; $61 \%$ of on cell dendritic branch segments had one or more serotonergic appositions. This pattern is reflected in the pattern of appositions onto primary and secondary dendritic branch segments. For primary dendrites, $62 \%$ of serotonergic neutral cell, $59 \%$ of off cell, and $42 \%$ of on cell dendritic branches received at least one apposition. For secondary branches, $84 \%, 74 \%$, and $50 \%$ of serotonergic neutral, off and on cell segments, respectively, were found to have appositions.

Neutral cells had a higher proportion $(67 \%)$ of dendritic branches with a density of serotonergic appositions greater than the mean overall appositional density (7.00 appositions/1000 $\left.\mu \mathrm{m}^{2}\right)$ than did on $(29 \%)$ or off $(50 \%)$ cells.

\section{Control experiments}

In order to judge the reproducibility of the identification of appositions, an observer unfamiliar with the data reexamined a total of 25 pairs of optical sections. As detailed in Materials and Methods and in a previous report (Mason et al., 1992), 25 sections containing a stained neuron were randomly chosen. Each 

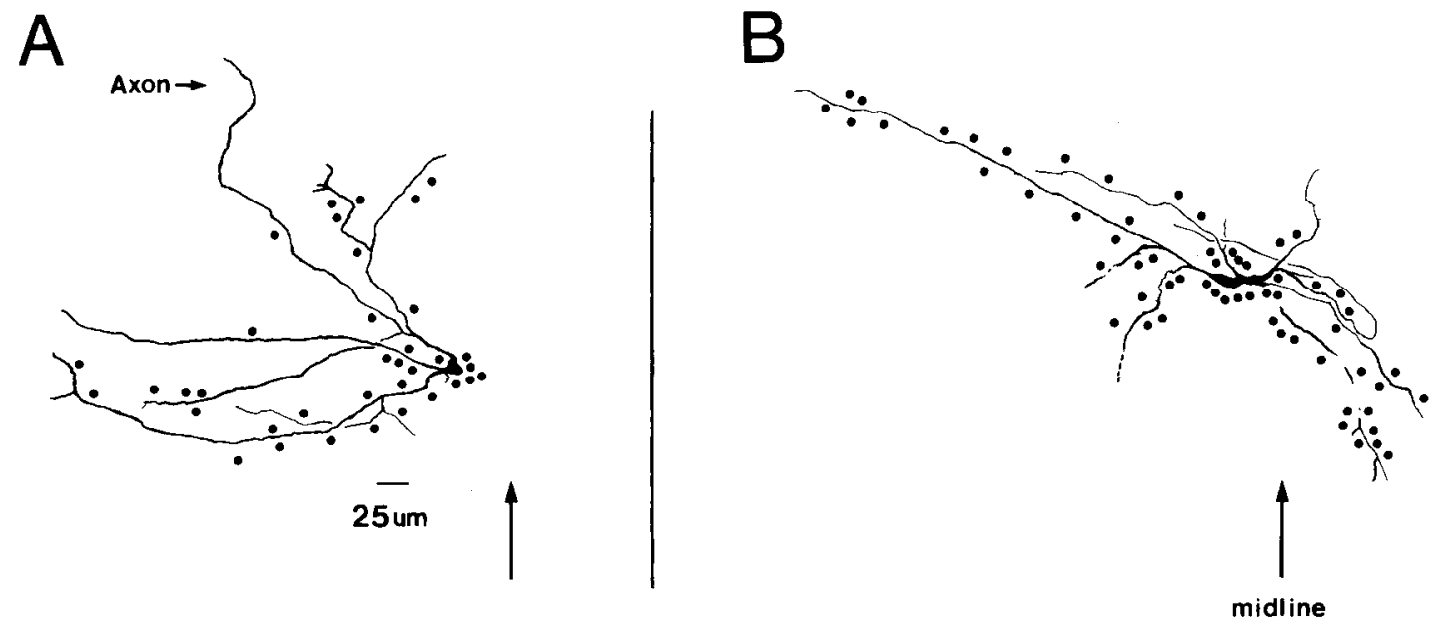

Figure 6. 5-HT-IR appositions onto two intracellularly labeled 5-HT-IR neutral cells. Each dot represents a single apposition. Note that the scale of these two reconstructions differs from that in Figure 4.
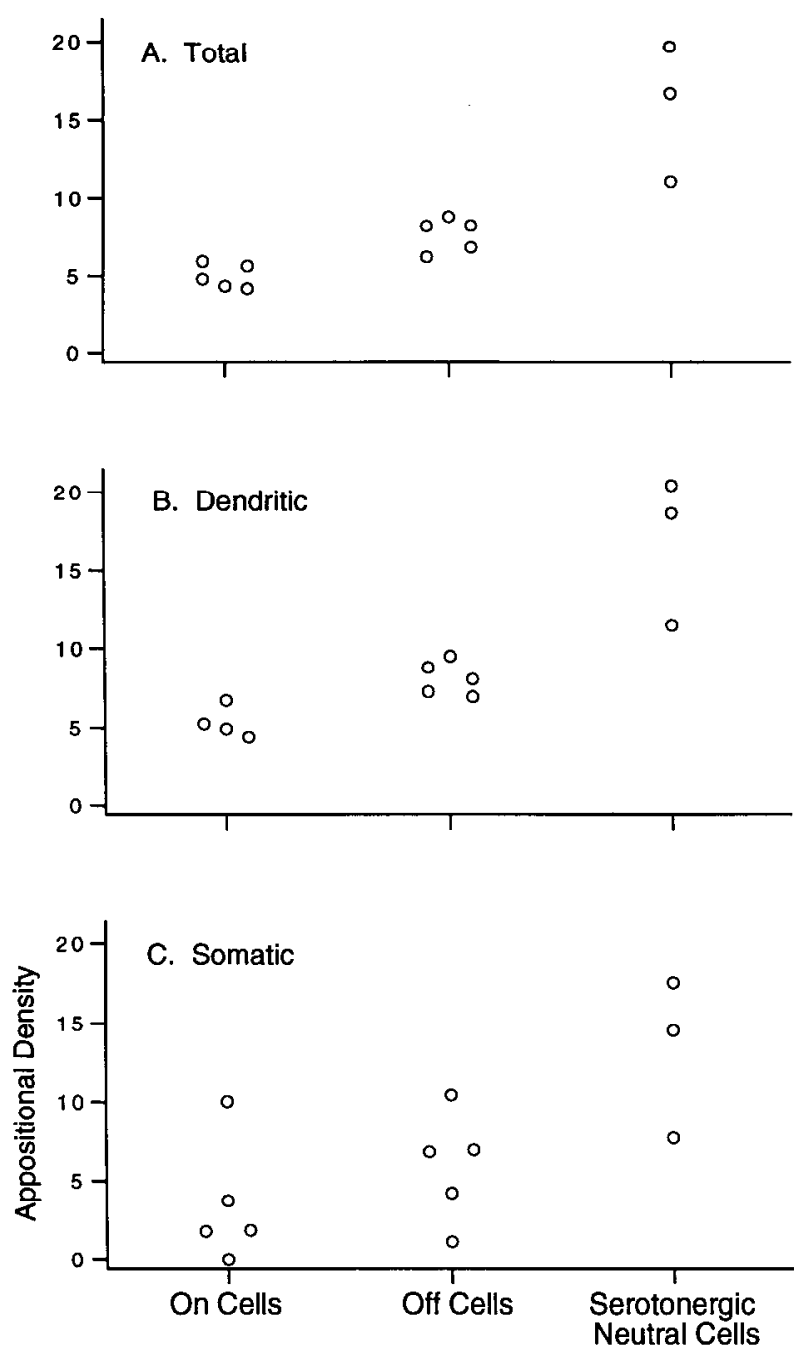

Figure 7. Scatter graphs show the density of 5-HT-IR appositions (per $1000{\mu \mathrm{m}^{2}}^{2}$ surface area) for the 13 intracellularly labeled neurons (five off, five on, and three serotonergic neutral cells). Each neuron is represented by an open circle. A, Total density is calculated from the total number of appositions on each neuron divided by the total surface area of that neuron. $B$, Dendritic density is the density of appositions found only on the dendrites. $C$, Somatic density is the density of 5-HT-IR appositions onto only the soma. optical section containing a labeled cell was then merged with an optical section of the 5-HT immunoreactivity that was located 6 frames $(\approx 11.4 \mu \mathrm{m})$ away. Of 13 optical sections judged not to contain appositions by the initial experimenter, the blinded observer also did not identify any appositions. In 12 optical files with 21 appositions identified by the initial observer, the sccond observer identified $20(95 \%)$. Additionally, the second observer noted a contact not identified initially.

In order to estimate the expected density of 5-HT-IR appositional profiles in the region of the intracellularly labeled RVM neurons, a variant of the "frame-shifted merge" method of Mason et al. (1992) was used. Briefly, randomly selected optical sections containing a Texas red labeled intracellular process were merged with optical sections of the 5-HT-IR signal from an entirely separate focal plane (Mason et al., 1992). The density of appositions onto a segment of labeled neuron is then a measure of the expected occurrence of appositions with respect to the density of the afferent label. The mean density of appositions calculated in a series of frame shifted merges from three RVM neurons was $2.8 / 1000 \mu \mathrm{m}^{2}\left( \pm 2.5 / 1000 \mu \mathrm{m}^{2}, n=3\right.$ ). The density of appositions onto off and serotonergic neutral cells, but not on cells, differed significantly from the density found in the frame-shifted series (one-way ANOVA, $F[3,12]=21.0632, p$ $<0.0001$, Tukey post hoc tests, $p=0.0002$ serotonergic neutrals vs frame shifts, $p=0.0460$ offs vs frame shifts, $p=0.5526$ ons vs frame shifts).

\section{Discussion}

We have demonstrated that RVM 5-HT-IR neutral cells receive the highest density of 5-HT-IR appositions of all RVM cell types examined. This intriguing result suggests that the activity of serotonergic cells is regulated by 5 -HT release. In addition, we have found that RVM off cells receive a significantly higher density of appositions than is predicted by the density of 5-HT afferents alone. Since off cells contribute to pain modulation, these results support the hypothesis that RVM serotonergic afferents are involved in nociceptive modulation.

\section{Technical considerations}

Compared to standard fluorescent microscopy, confocal laser scanning microscopy (CLSM) both improves optical resolution in the $x-y$ plane (see Fig. 3 in Mason et al., 1992) and permits 

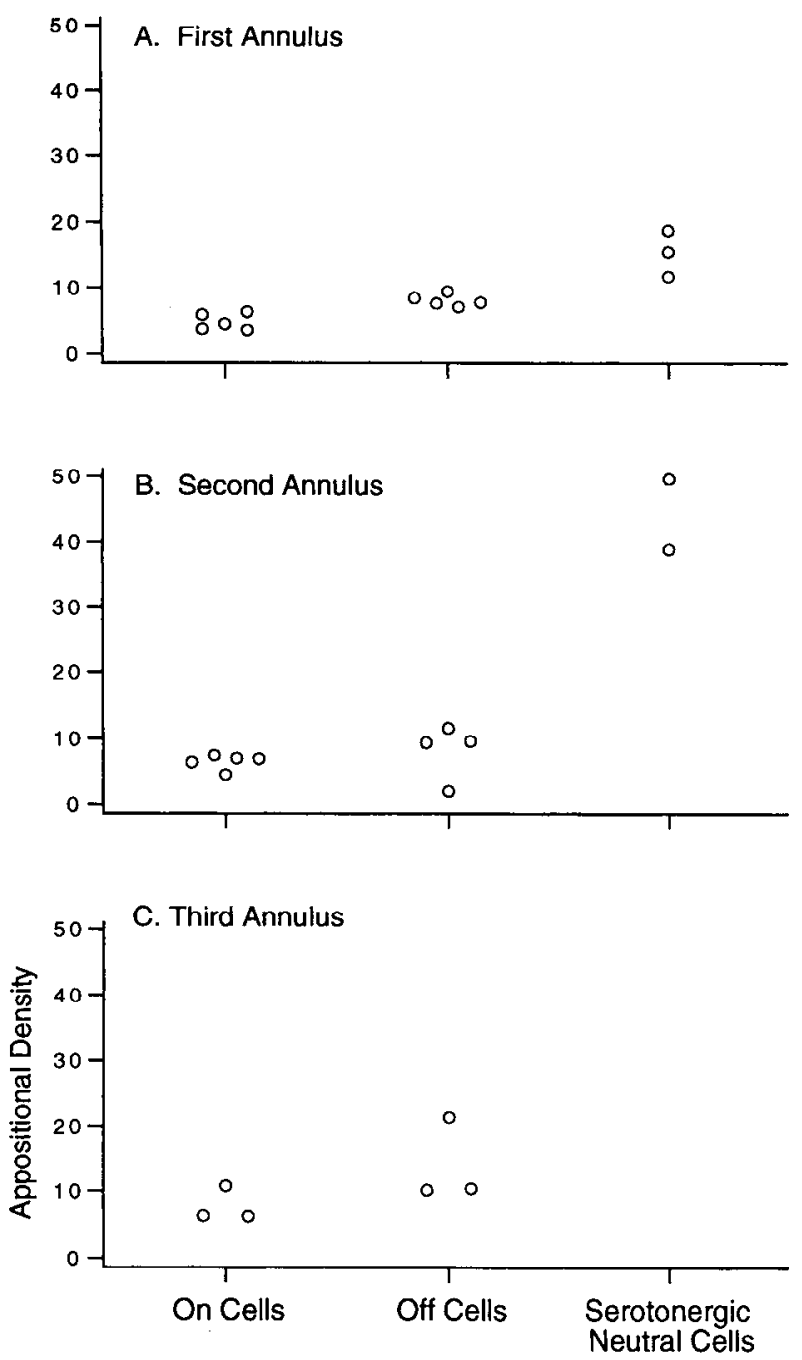

Figure 8. Scatter graphs show the density of 5-HT-IR appositions (per $1000 \mathrm{\mu m}^{2}$ surface area) for the intracellularly labeled neurons as a function of distance from the soma. Each annulus represents $250 \mu \mathrm{m}$ of dendritic length (see Materials and Methods).

optical thin sectioning in the z-axis (Pawley, 1990). Furthermore, as compared to electron microscopy, working at the light microscope level permits more efficient analysis of the distribution of inputs over a large extent of a neuron's somatodendritic domain.

CLSM was used in this study to identify appositions between intracellularly labeled processes and 5-HT-IR profiles in z-axis optical sections of $1.5-1.9 \mu \mathrm{m}$. This technique will overestimate serotonergic input since not all appositions are sites of synaptic contact. Although, we cannot determine the percentage of appositions that correspond to synapses, 5-HT-IR synapses onto RVM neurons have been described at the ultrastructural level (Chazal and Ma, 1989). Furthermore, the overestimation of synaptic contacts introduced by our CLSM method is likely to be the same for all neuronal classes since similar aperture settings wcre employed in scanning all cells.

Appositions, as defined in the present study, are likely to include classical synapses as well as profiles that, at the resolution of the light microscope, actually appose the labeled neuron but would be seen to lack the identifying features of classical synapses if they could be viewed at the EM level. Since the optical sections being examined represent a volume of tissue that is approximately $1.9 \mu \mathrm{m}$ thick, it is likely that some contacts that are called appositions represent apparent overlap in the $x-y$ plane but would be seen to not make contact if viewed in an $x-z$ or $y-z$ plane. These would clearly not be considered contacts in an anatomical sense. It is important to point out that because of the possibility of volume transmission, nearby but nonsynaptic 5-HT-IR appositions could represent functional transmitter release sites for the postsynaptic neuron. Purely anatomical criteria are insufficient to determine the functional significance of such appositions. However, if 5-HT-IR appositions were targeted upon a specific class of RVM neurons, their density might be expected to be significantly higher than can be accounted for by the overall density of 5-HT-IR appositional profiles in the RVM.

Serotonergic neutral cells in our sample are smaller than other cells. Thus, it is possible that the greater overall appositional density found onto serotonergic neutral cells is due to incomplete filling of distal dendrites. Ilowever, the differences in density among the cell groups hold if the appositional density in the central and second annuli of the different cell types are compared.

In our sample, neutral cells were located more ventrally than the on or off cells. While there may be a higher density of 5-HT terminals in this region, this is unlikely to account for our results since a ventrally located non-5-HT neutral cell received a low density of 5-HT-IR appositions.

\section{Comparison with previous results}

Our results indicate that $\mathrm{RVM}$ serotonergic neurons receive serotonergic afferent input. Similar results have been noted in cats (Pretel and Ruda, 1988). However, our result is in apparent conflict with a study examining the fine structure of rat RVM serotonergic processes. Chazal and Ma (1989) did not find serotonergic terminals contacting serotoncrgic somata or proximal dendrites in rat raphe magnus. Since glutaraldehyde, which greatly reduces serotonergic terminal staining, was present in the fixative used in the Chazal and Ma study, it is possible that many 5-HT-IR boutons were unlabeled. If this were true, many, if not most, 5-HT-IR synapses would not appear immunoreactive.

\section{Serotonergic Influences on RVM cell activity}

All neurons in RVM received 5-HT-IR appositions. Two classes of RVM neurons, off and serotonergic neutral cells, received a significantly higher density of 5-HT-IR appositions than would be predicted by the density of serotonergic afferents in RVM. Although it is difficult to interpret the functional significance of a given appositional density, comparison with other neurotransmitters may be meaningful. For example, the density of serotonergic appositions onto serotonergic RVM neutral cells is approximately five fold greater than the density of enkephalinergic appositions onto on cells, the RVM population with the greatest density of enkephalinergic input (Mason et al., 1992).

Serotonergic neutral cells. It is unclear whether the serotonergic appositions onto serotonergic neutral cells contribute to nociceptive modulation, largely because the role of serotonergic neutral cells is still imprecisely defined. In anesthetized rats, RVM neutral cell activity is not consistently altered by noxious stimulation (Fields et al., 1983a) or by systemic, supraspinal, or local administration of opioids (Barbaro et al., 1986; Cheng et al., 1986; Fang et al., 1989; Heinricher et al., 1992). On the other hand, since 5-HT within the spinal cord has primarily inhibitory effects on nociception (Yaksh and Wilson, 1979; Fields and Basbaum, 1984; Sawynok, 1988) serotonergic neutral cells 
may contribute to the inhibition of nociception (Potrebic et al., 1994).

Little is known about 5-HT's effects on neutral cell activity. In an in vivo study combining microinjection with extracellular recording, local infusion of a 5- $\mathrm{HT}_{1 \mathrm{~A}}$ agonist, 8-0H DPAT, suppressed neutral cell activity (Heinricher et al., 1993). In vitro studies also suggest that 5-HT directly hyperpolarizes opioidinsensilive neurons, a population which likely includes neutral cells (Pan et. al., 1990). In interpreting these results, it is important to remember that the in vivo electrophysiological study was not able to distinguish between serotonergic and nonserotonergic neutral cells while the in vitro study did not distinguish between off and neutral cells. Therefore, it is likely that recordings were made from mixed populations in both experiments.

The finding that serotonergic neutral cells receive a high density of 5-HT-IR appositions suggests that 5-HT plays an important role in controlling the activity of these cells. Although most studies concerning presynaptic regulation of 5-HT release by 5-HT have focused on receptors located on axonal terminals, the somata and dendrites of serotonergic neurons also have 5-HT receptors (Chesselet, 1984; Jacobs and Azmitia, 1992). The differential roles of autoreceptors on terminals or somata and dendrites have not been elucidated. While the present results do not address this question directly, they suggest that an action of $5-\mathrm{HT}$ at the soma and dendrites of serotonergic RM/NRPG $\alpha$ neurons is likely to be important. In order to delineate the specific role of these connections, future studies will need to identify (1) the source of the serotonergic afferents to serotonergic neutral cells and (2) the 5-HT receptor subtypes located on the serotonergic neutral cells.

Off cells. Since off cells receive a significant serotonergic innervation and are hypothesized to contribute to antinociception, RVM serotonergic afferents to off cells may contribute to nociceptive modulation. Electrophysiological studies provide evidence for a primarily inhibitory effect of 5-HT upon off cells. Primary neurons recorded in the RVM slice are not directly affected by opioids but receive a GABAergic IPSP that is decreased by opioids; these cells likely correspond to off cells in vivo since off cell activity is excited by analgesic doses of opioids but is not affected by iontophoretic application of opioids (Heinricher et al., 1992). In the RVM slice preparation, $84 \%$ of "primary" neurons were hyperpolarized by perfusion of 5-HT, whereas $11 \%$ were depolarized (Pan et al., 1993). In addition, iontophoretic application of 5-HT reduces the spontaneous activity of RVM off cells in the rat (Hentall et al., 1993). The behavioral antinociceptive effect reported to result from 5-HT microinjection into RVM (see introductory section) would not be predicted from the observed electrophysiological inhibition of off cells and their hypothesized nociceptive inhibitory effect.

On cells. Serotonergic appositions were found onto on cells at a density that was not different than from that predicted by the overall density of 5-HT profiles in the RVM. Although these anatomical data do not allow us to determine the physiological significance of 5-HT input to on cells, there is evidence suggesting that on cell activity can be modulated by 5 HT. In the slice, most "secondary cells" (Pan et al., 1990), neurons that are directly hyperpolarized by opioids and likely correspond to on cells, are hyperpolarized by 5-HT (Pan et al., 1992). Since on cells are postulated to facilitate nociception (Fields, 1992) their inhibition could contribute to an antinociceptive action. However, "on-like" cells recorded in vivo showed more varied changes in activity following iontophoresis of 5-HT: excitation $(40 \%)$, inhibition $(30 \%)$, and inhibition followed by excitation (25\%) (Hentall et al., 1993).

\section{Influences of 5-HT in RVM on nociceptive modulation}

As summarized in the introduction, some evidence suggests that the activation of serotonergic afferents to RVM neurons results in the inhibition of nociceptive transmission. This antinociceptive effect is presumably mediated through changes in the activity or response characteristics of RVM output neurons. However, as discussed above, the described actions of 5-HT on presumed RVM modulatory neurons do not consistently predict an antinociceptive effect of RVM 5-HT.

The electrophysiological effect of 5-HT on an RVM neuron will depend on the receptors expressed by the postsynaptic cell and presynaptic terminal, while the behavioral effect of 5-HT release depends additionally on the source of the 5-HT afferent and the conditions under which that afferent is active. Anatomical studies have demonstrated the presence of $5-\mathrm{HT}_{\mathrm{IA}}$ binding sites (Thor et. al., 1990), 5-HT $\mathrm{IC}_{\mathrm{C}}$ receptors (Hoffman and Mezey, 1989) and 5-HT 2 binding sites (Pazos et al., 1985). Within RVM, 5 -HT can have either excitatory effects via $5-\mathrm{HT}_{2 / 1 \mathrm{C}}$ receptors (Davies et al., 1988a), or inhibitory effects, via 5-HT ///A $_{\text {recep- }}$ tors (Davies et al., 1988b; Pan et al., 1993). In addition, 5-HT afferents to RVM originate from several sources, including the B7, B8, and B9 cell groups (Beitz, 1982).

Another source of variability in 5-HT's influences on RVM neurons and behavior may be derived from the complex modulatory effect of 5-HT. 5-HT may have little or no effect on a neuron's spontaneous activity while dramatically altering evoked responses. For example, in rat facial nucleus, microiontophoresis of 5-HT fails to excite facial motoneurons but facilitates the excitatory responses evoked by either glutamate application or afferent stimulation (McCall and Aghajanian, 1979). Similarly, in rat somatosensory cortex, microiontophoresis of 5-HT reduces the excitation evoked by mechanical displacement of the skin to a greater extent than the spontaneous activity (Waterhouse et al., 1986).

In summary, the effects of 5-HT on RVM neurons likely depend on both the type and distribution of 5-HT receptors and their location on different RVM cell classes and afferents. Thus, information about the sources of serotonergic input to each cell class as well as the complement of receptors expressed by neurons of each type will be required for a full appreciation of the mechanisms by which serotonergic afferents affect RVM modulatory outputs.

\section{References}

Aimone LD, Gebhart GF (1986) Stimulation-produced spinal inhibition from the midbrain in the rat is mediated by an excitatory amino acid neurotransmitter in the medial medulla. J Neurosci 6:1803-1813.

Barbaro NM, Heinricher MM, Fields HL (1986) Putative nociceptive modulatory neurons in the rostral ventral medulla: reflex activity predicts effects of morphine. Brain Res 366:203-210.

Basbaum AI, Fields HL (1984) Endogenous pain control systems: brainstem spinal pathways and endorphin circuitry. Annu Rev Neurosci 7:309-328

Beitz AJ (1982) Sites of origin of brain stem neurotensin and serotonin projections to the rodent nucleus raphe magnus. J Neurosci 2:829 842

Chazal G, Ma W (1989) An ultrastructural analysis of serotonergic neurons in the nucleus raphe magnus of the rat. Neuroscience 33: 301-310.

Cheng ZF, Fields HL, Heinricher MM (1986) Morphine microinjected 
into the periaqueductal gray has differential effects on 3 classes of medullary neurons. Brain Res 366:203-210.

Chesselet M-F (1984) Presynaptic regulation of neurotransmitter release in the brain: facts and hypothesis. Neuroscience 12:347-375.

Davies M, Wilkinson LS, Roberts MHT (1988a) Evidence for excitatory $5-\mathrm{HT}_{2}$ receptors on rat brainstem neurones. Br J Pharmacol 94: 483-491.

Davies M, Wilkinson LS, Roberts MHT (1988b) Evidence for depressant 5-HT, - like receptors on rat brainstem neurones. $\mathrm{Br}$ I Pharmacol 94:492-499.

Fang FG, Haws CM, Drasner K, Williamson A, Fields HL (1989) Opioid peptides (DAGO-cnkephalin, dynorphin A(1-13), BAM 22P) microinjected into the rat brainstem: comparisons of their antinociceptive effects and their effect on neuronal firing in the rostral ventromedial medulla. Brain Res 501:116-128.

Fields HL (1992) Is there a facilitating component to central pain modulation? APS J 1:139-141.

Fields HL, Basbaum AI (1978) Brainstem control of spinal pain transmission neutrons. Annu Rev Physiol 40:217-248.

Fields HL, Bry J, Hentall ID, Zorman G (1983a) The activity of neurons in the rostral medulla of the rat during withdrawal from noxious heat. J Neurosci 3:254-52.

Fields HL, Vanegas H, Hentall ID, Zorman G (1983b) Evidence that disinhibition of brain stem neurones contributes to morphine analgesia. Nature 306:684-686.

Fields HL, Heinricher MM, Mason P (1991) Neurotransmitters in nociceptive modulatory circuits. Annu Rev Neurosci 14:219-245.

Fuxe K (1965) Evidence for the existence of monoamine-containing neurons in the central nervous system. IV. Distribution of monoamine nerve terminals in the CNS. Acta Physiol Scand [Suppl] 247:37-80.

Heinricher MM, Morgan MM, Fields HL (1992) Direct and indirect actions of morphine on medullary neurons that modulate nociception. Neuroscience 48:533-543.

Heinricher MM, Potrebic S, Zagon A, Fields HL (1993) Direct local application of a $5-\mathrm{HT}_{1 \mathrm{~A}}$ agonist in rostroventral medulla of the lightly anesthetized rat: effects on neuronal activity, blood pressure and nociceptive responsiveness. 7 th World Congress on Pain.

Hentall ID, Andersen MJ, Taguchi K (1993) Serotonergic, cholinergic and nociceptive inhibition or excitation of raphe magnus neurons in barbiturate-anesthetized rats. Neuroscience 52:303-310.

Hoffman BJ, Mezey E(1989) Distribution of serotonin 5-HT Ic receptor $m R N \Lambda$ in adult rat brain. FEBS Lett 247:453 462.

Jacobs BL, Azmitia EC (1992) Structure and function of the brain serotonin system. Physiol Rev 72:165-229.

Kiefel JM, Cooper ML, Bodnar RJ (1992a) Inhibition of mesencephalic morphine analgesia by methysergide in the medial ventral medulla of rats. Physiol Behav 51:201-205.

Kiefel JM, Cooper ML, Bodnar RJ (1992b) Serotonin receptor subtype antagonists in the medial ventral medulla inhibit mesencephalic opiate analgesia. Brain Res 597:331-338.

Le Bars D (1988) Serotonin and pain. In: Neuronal serotonin (Osborne NN, Hamon M, eds), pp 171-226. New York: Wiley.

Llewelyn MB, Azami J, Roberts MHT (1983) Effects of 5-hydroxytryptamine applied into nucleus raphe magnus on nociceptive thresholds and neuronal firing rate. Brain Res 258:59-68.

Llewelyn MB, Azami J, Roberts MHT (1984) The effects of modifi- cation of 5-hydroxytryptamine function in nucleus raphe magnus on nociceptive threshold. Brain Res 306:165-170.

Mason P, Fields HL (1989) Somatodendritic morphology of on- and off-cells in the rostral ventromedial medulla. J Comp Ncurol 301:2343.

Mason P, Strassman A, Maciewicz R (1986) Intracellular responses of raphe magnus neurons during the jaw opening reflex evoked by tooth pulp stimulation. Brain Res 379:232-241.

Mason P, Floeter MK, Fields HL (1990) Axonal trajectories and terminations of on- and off-cells in the lower brainstem of the cat. J Comp Neurol 288:185-207.

Mason P, Back SA, Fields HL (1992) A confocal laser microscopic study of enkephalin-immunoreactive appositions onto physiologically identified neurons in the rostral ventromedial medulla. J Neurosci 12: 4023-4036.

McCall RB, Aghajanian GK (1979) Serotonergic facilitation of facial motorneuronal excitation. Brain Res 169:11-27.

Pan 7.7., Williams JT, Osborne PB (1990) Opioid actions on single nucleus raphe magnus neurons from rat and guinea pig. J Physiol 427:519-532.

Pan ZZ, Wessendorf MW, Williams JT (1993) Modulation by serotonin of the neurons in rats nucleus raphe magnus in vitro. Neuroscience $54: 421-430$

Pawley JB (1990) Fundamental limits in confocal microscopy. In: Handbook of biological confocal microscopy (Pawley JB, ed), pp $15-$ 26. New York: Plenum.

Paxinos G, Watson C (1986) The rat brain in stereotaxic coordinates. New York: Academic.

Pazos A, Cortes R, Palacois JM (1985) Quantitative autoradiographic mapping of serotonin receptors in the rat brain. II. Serotonin-2-receptors. Brain Res 346:231-249.

Potrebic S, Mason P (1993) Three dimensional analysis of the dendritic domains of on-cells and off-cells in the rostral ventromedial medulla. J Comp Neurol 337:83-93.

Potrebic SB, Fields HL, Mason P (1994) Serotonin immunoreactivity is contained in one physiological cell class in the rat rostral ventromedial medulla. J Neurosci 14:1655-1665.

Pretel S, Ruda MA (1988) Immunocytochemical analysis of noradrenaline, substance $P$, and enkephalin axonal contacts on serotonin neurons in the caudal raphe nuclei of the cat. Neurosci Lett 89:19-24.

Rivot JP, Pontis D, Besson JM (1989) A comparison of the effect of morphine on 5-HT metabolism in the periaqueductal gray, nucleus raphe magnus, and medullary dorsal horn: an in vivo electrochemical study in freely moving rats. Brain Res 495:140-144.

Sawynok J (1988) The role of ascending and descending noradrenergic and serotonergic pathways in opioid and non-opioid antinociception as revealed by lesion studics. Can J Pharmacol 67:975-988.

Steinbusch HWM (1981) Distribution of serotonin immunoreactivity in the central nervous system of the rat-cel! bodies and terminals. Neuroscience 6:557-618.

Thor TB, Blitz-Siebert A, Helke CJ (1990) Discrete localization of high density $5-\mathrm{HT}_{1 \mathrm{~A}}$ binding sites in midline raphe and parapyramidal regions of ventral medulla oblongata of rats. Brain Res 408:249-25I

Waterhouse BD, Moises HC, Woodward DJ (1986) Interaction of serotonin with somatosensory cortical neuronal responses to afferent synaptic inputs and putative neurotransmitters. Brain Res Bull 17: $507-518$.

Yaksh TL, Wilson TR (1979) Spinal serotonin terminal system mediates antinociception. J Pharmacol Exp Ther 208:446-453. 